\title{
Threading/Folding Recognition Modes of Phosphodiesters by a $p$-Nitrophenylamide Cyclodextrin Derivative
}

\author{
Sota Yonemura, ${ }^{1}$ Takashi Nakamura, ${ }^{1}$ and Tatsuya Nabeshima*1 \\ ${ }^{1}$ Graduate School of Pure and Applied Sciences and Tsukuba Research Center for Energy Materials Science (TREMS), \\ University of Tsukuba, 1-1-1 Tennodai, Tsukuba, Ibaraki 305-8571, Japan
}

E-mail: nabesima@chem.tsukuba.ac.jp

\begin{abstract}
A cyclodextrin derivative $\mathbf{1}$ possessing multiple $p$ nitrophenylamide groups, which is a strong hydrogen-bond donor, encapsulates phosphodiester anions in two recognition modes. One is the 'threading' mode, in which the phosphodiester passes through the cyclodextrin cavity. The other is the 'folding' mode, in which the included phosphodiester is bent inside the cyclodextrin cavity. The tendency between the two recognition modes depends on the substituents on the phosphodiesters.
\end{abstract}

\section{Keywords: Amide, Cyclodextrin, Anion receptor}

The precise molecular recognition by proteins is realized by multiple hydrogen bonds utilizing amino acid side chains and backbone amide groups which are accumulated inside the recognition pocket. ${ }^{[1-5]}$ Inspired by nature, many artificial receptors whose interaction moieties are closely arranged to each other have been reported. ${ }^{[6-13]}$ In particular, amide groups have been widely used for such receptors, because they can be easily introduced and ubiquitously found in biological molecules. ${ }^{[14-21]}$

Fixing the position, orientation, and conformation of the encapsulated molecules via multiple non-covalent bonds is important for the precise recognition and catalytic functions. ${ }^{[22-24]}$ Phosphodiester groups are found ubiquitously in biological molecules such as DNA and phospholipids. To understand and mimic the functions of phosphodiesterases, the artificial host molecules that recognize or hydrolyze diaryl phosphates as model compounds have been investigated. ${ }^{[25-27]}$ Host molecules that recognize a phosphodiester in a specific conformation would contribute to the development of selective phosphate transporters and artificial enzymes.

We have previously reported a cyclodextrin derivative 2 whose amide groups are directly attached to the pyranose units. ${ }^{[28]} 2$ possesses seven $p$-tolylamide groups. Although they are in close proximity, they formed only partial intramolecular hydrogen bonds to each other because of the conformational restriction by the cyclodextrin framework and the steric hindrance of the accumulated aromatic rings. This contributes to the effective intermolecular hydrogen bonds between the amides and the substrate included in the cavity. It is notable that the selective recognition of hydrogen phosphonate anions has been achieved by utilizing chemically equivalent amide groups both as a hydrogen-bond donor and acceptor.

It is known that the introduction of electronwithdrawing groups on aromatic amide or urea units leads to a greater superior hydrogen-bonding ability by lowering the electron density of the N-H bond. ${ }^{[6,15]}$ We have now
49 synthesized a novel cyclodextrin derivative 1 possessing 50 seven $p$-nitrophenyl groups with the objective of producing a 51 unique recognition ability for anions (Figure 1a). It was 52 revealed that the receptor $\mathbf{1}$ has a double-conical-shaped 53 recognition pocket consisting of two distinct cavities on each 54 side of the central amide moieties. The 'first' one is the 55 normal cyclodextrin's cavity surrounded by the pyranose 56 units. The 'second' one is on its other side, and is surrounded 57 by the electron-deficient aromatic rings. With this feature, 58 the receptor 1 exhibited two unique recognition modes for the 59 inclusion of phosphodiesters with different conformations, 60 that is, a 'threading' mode and a 'folding' mode (Figure 1b).

(a)

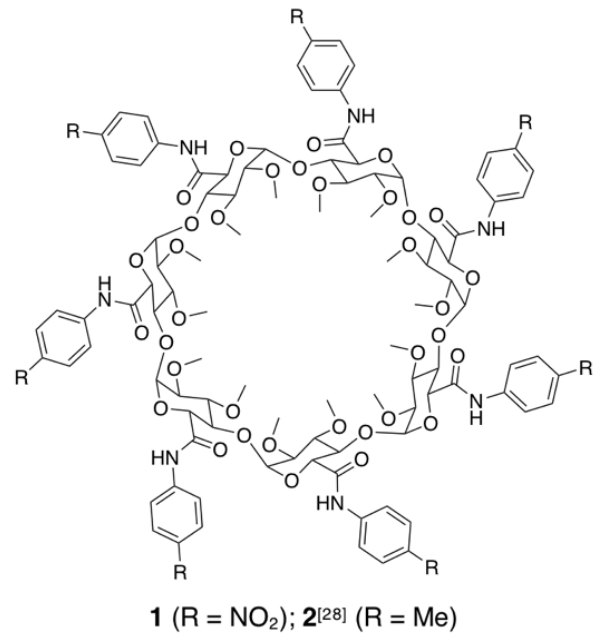

(b)
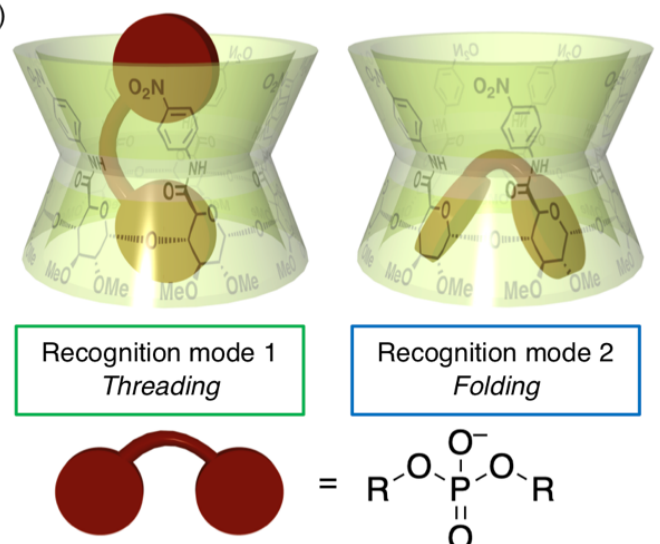

61

62 Figure 1. (a) Structures of aromatic-amide cyclodextrin derivatives. 63 (b) Schematic representation of the two recognition modes of 64 phosphodiesters by 1 . 
1 Receptor $\mathbf{1}$ was synthesized by the condensation 2 reaction of a per(5-carboxy-5-dehydroxymethyl)- $\beta$ 3 cyclodextrin derivative ${ }^{[29]}$ and $p$-nitroaniline (Scheme $\mathrm{S} 1$, 4 Figures S1-S7). A ${ }^{1} \mathrm{H}$ NMR signal of the amide proton of $\mathbf{1}$ 5 was observed at $9.00 \mathrm{ppm}\left(\mathrm{CD}_{3} \mathrm{CN}\right)$, which is a good 6 indicator for its participation in the hydrogen bonding.

We first briefly investigated whether 1 exhibits a stronger binding of anions than 2. ${ }^{1} \mathrm{H}$ NMR titration experiments confirmed that $1(0.80 \mathrm{mM})$ quantitatively encapsulated $p$-toluenesulfonate, acetate, and chloride in a $1: 1$ manner $\left(K_{\mathrm{a}}>10^{4} \mathrm{M}^{-1}, \mathrm{CDCl}_{3}\right)$ (Figures S8-S10), which is in contrast to the weak or no binding of the three anions by $2\left(K_{\mathrm{a}}<10^{2} \mathrm{M}^{-1}\right)^{[28]}$. This can be attributed to the superior hydrogen-bonding ability of receptor 1 .

The interaction between the diphenyl phosphate anion $\left(3^{-}\right)$and 1 was then investigated. The diphenyl phosphate anion showed no binding toward $\mathbf{2}$ in a previous study. ${ }^{[28]} \mathrm{A}$ ${ }^{1} \mathrm{H}$ NMR titration experiment of tetrabutylammonium diphenyl phosphate $\left(\left(n-\mathrm{Bu}_{4} \mathrm{~N}\right) 3\right)$ against 1 in a $\mathrm{CD}_{3} \mathrm{CN}$ solution $(0.80 \mathrm{mM})$ was performed (Figure $2 \mathrm{a}-\mathrm{c}$, Figure $\mathrm{S} 11)$. Upon the addition of 1 equivalent of $\left(n-\mathrm{Bu}_{4} \mathrm{~N}\right) 3$, the signals of the free host molecule 1 disappeared, and two new sets of signals of the host-guest complexes were observed. The ${ }^{1} \mathrm{H}$ signals of the amide N-H were shifted from 9.00 to $9.98 \mathrm{ppm}$ and $10.00 \mathrm{ppm}$. This downfield shift indicated the formation of hydrogen bonds between the amides and the phosphate. During the course of the titration experiment, the ratio of these two complexes was constant $(58 \% / 42 \%)$ irrespective of the amount of $3^{-}$. The integration ratio of the ${ }^{1} \mathrm{H}$ signals 1 and $3^{-}$revealed that both species are 1:1 complexes. For the major complex $(58 \%)$, two phenyl groups of $3^{-}$were separately observed by ${ }^{1} \mathrm{H}$ NMR, and ROE correlations to the pyranose unit of the cyclodextrin were observed for only one of the two phenyls (Figure 2d, Figure S24). For the minor complex (42\%), two phenyl groups are chemically equivalent in the ${ }^{1} \mathrm{H}$ NMR spectrum, and they showed ROE correlations to the sugar unit. These results suggest that the major species $(58 \%)$ is a complex in which the guest is threaded through the cyclodextrin cavity (Recognition mode 1 in Figure 1b), while the minor species (42\%) is a complex in which the guest is folded in the cyclodextrin's cavity (Recognition mode 2 in Figure 1b). Chemical shifts of the ${ }^{31} \mathrm{P}$ NMR signals of the two complexes are different by more than 5 ppm ( -5.61 and $-10.68 \mathrm{ppm}$, respectively), which also supports the two distinctive recognition modes of the phosphate (Figure S23). The two species are separately observed by ${ }^{1} \mathrm{H}$ NMR even at high temperature $(343 \mathrm{~K})$, which shows a slow conversion and high energy barrier between these complexes (Figure S26).
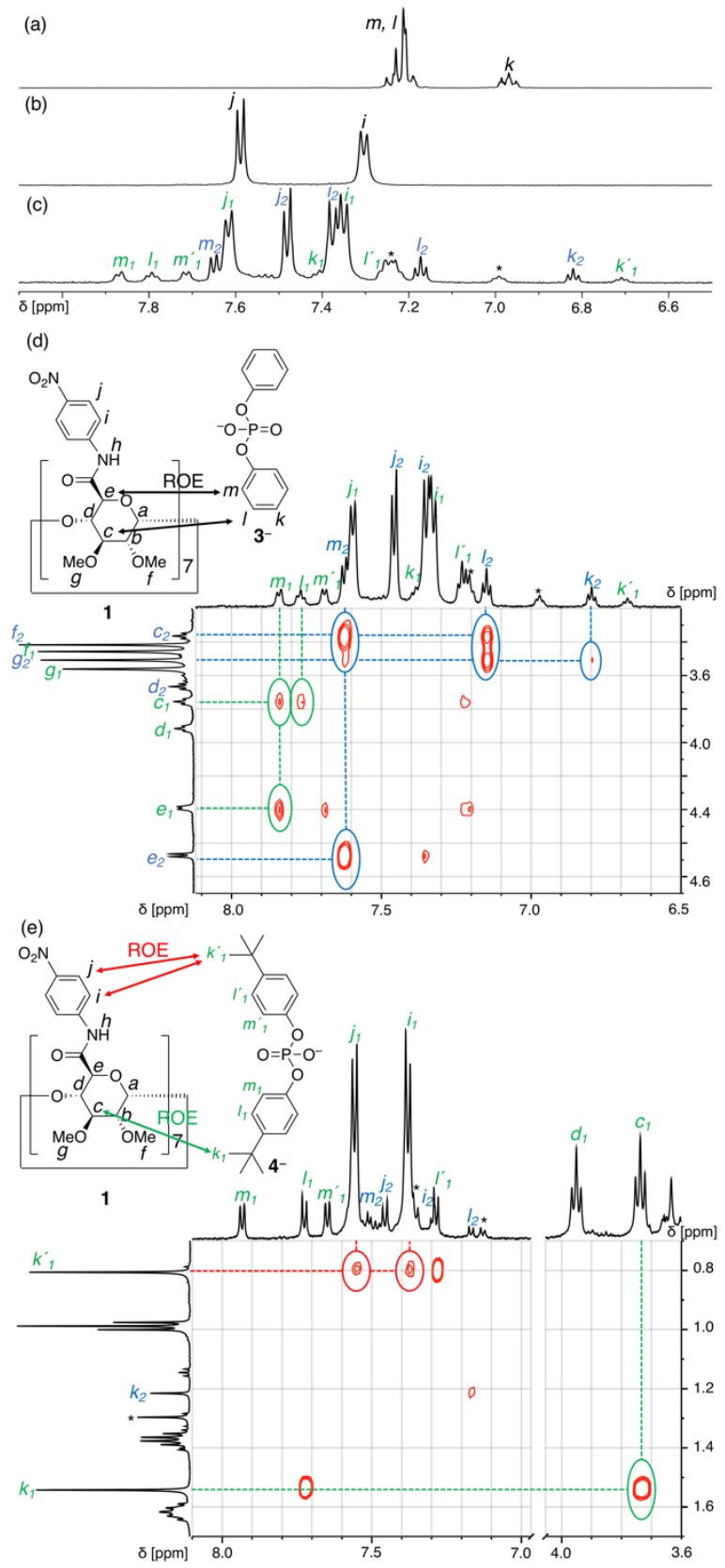

Figure 2. Recognition of phosphodiesters by 1. (a)-(c) ${ }^{1} \mathrm{H}$ NMR spectra of aromatic region $\left(600 \mathrm{MHz}, \mathrm{CD}_{3} \mathrm{CN}\right)$. (a) $(n-\mathrm{Bu} 4 \mathrm{~N})\left(\mathrm{PhO}-\mathrm{PO}_{2}{ }^{-}-\mathrm{OPh}\right)$ $\left(\left(n-\mathrm{Bu}_{4} \mathrm{~N}\right) \mathbf{3}\right)$. (b) $\mathbf{1}(0.8 \mathrm{mM})$. (c) $\mathbf{1}$ and $\left(n-\mathrm{Bu}_{4} \mathrm{~N}\right) \mathbf{3}(1.3 \mathrm{eq})$. Protons of the host-guest complex in the 'threading' mode are denoted by green letters with subscript 1 . Protons of the phenyl group of $\mathbf{3}^{-}$in the nitrophenyl group's cavity are denoted with primed letters, and those in the cyclodextrin's cavity are denoted with letters without prime. Protons of the host-guest complex in the 'folding' mode are denoted by blue letters with subscript 2 . $^{*}$ indicates $\mathbf{3}^{-}$that is not encapsulated in $\mathbf{1}$. (d) and (e) ${ }^{1} \mathrm{H}-{ }^{1} \mathrm{H}$ ROESY spectra $\left(600 \mathrm{MHz}, \mathrm{CD}_{3} \mathrm{CN}\right)$. (d) $\mathrm{ROE}$ correlations between aromatic regions and sugar regions for the hostguest complex between 1 and $\left(n-\mathrm{Bu}_{4} \mathrm{~N}\right) \mathbf{3}$ (1.3 eq). (e) ROE correlations with tert-butyl group for the host-guest complex between 1 and (n$\left.\mathrm{Bu}_{4} \mathrm{~N}\right)\left(p-t-\mathrm{BuC}_{6} \mathrm{H}_{4} \mathrm{O}-\mathrm{PO}_{2}{ }^{-}-\mathrm{O}\left(p-t-\mathrm{BuC}_{6} \mathrm{H}_{4}\right)\right)\left(\left(n-\mathrm{Bu}_{4} \mathrm{~N}\right) 4\right)(1.3 \mathrm{eq}) . \quad \mathrm{Red}$ circles represent ROEs between $p$-nitrophenyl group of $\mathbf{1}$ and $t$-Bu group 
1 of $\mathbf{4}^{-}$, and a green circle represents that between the sugar moiety of $\mathbf{1}$ and $t$-Bu group of $\mathbf{4}^{-}$.

3

Table 1 summarizes the ratio of the two recognition modes for the various phosphodiesters, together with the 1:1 binding constants $K_{\mathrm{a}}\left[\mathrm{M}^{-1}\right]$ (the stoichiometry has been confirmed by the integral ratio of ${ }^{1} \mathrm{H}$ NMR signals of the inclusion complexes; see also Figures S11-S21). For $\mathbf{4}^{-}$, which has a bulky $t$-Bu group at the $p$-position of the benzene ring, the equilibrium was biased toward the 'threading' mode ('threading'/'folding' $=87 \% / 13 \%$ ). Steric hindrance of the $t$-Bu group would have destabilized the folded conformation of $4^{-}$inside the cyclodextrin's cavity. In the 'threading' mode, a ${ }^{1} \mathrm{H}$ NMR signal assigned to one of the $t$ - $\mathrm{Bu}$ groups was shifted downfield (from $1.29 \mathrm{ppm}$ to $0.81 \mathrm{ppm}$ ) as the result of the shielding effects from the surrounding $p$-nitrophenyl groups. The structure of the 'threading' mode was further supported by the ROE correlation between the $t$-Bu group of $4^{-}$and the nitrophenyl groups of receptor 1 (Figure 2e, Figure $\mathrm{S} 25$ ). For $\mathbf{5}$, to which a methoxy group is introduced at the $p$-position of the benzene ring, the recognition mode was also biased toward the 'threading' mode $(72 \% / 28 \%)$. Meanwhile, the 'folding' mode was slightly favored in the case of the electron-deficient $p$-nitrophenyl phosphodiester 6 $(47 \% / 53 \%)$. The comparison of $\mathbf{3}^{-}, \mathbf{5}^{-}$, and $\mathbf{6}^{-}$suggested that the electron-rich substituent on the phosphodiesters might have stabilized the 'threading' mode through the intermolecular interactions with the electron-deficient $p$ nitrophenyl groups of $\mathbf{1}$. Interestingly, for the non-phenolic derivatives, dibenzyl phosphate $\mathbf{7}^{-}$and dibutyl phosphate $\mathbf{8}^{-}$, the recognition modes were biased toward the 'folding' mode (41\%/59\%, 10\%/90\%, respectively). These results can be explained as the result of the easiness of the flexible diphosphate molecules to take a folded conformation in the cyclodextrin's cavity. The binding constants $K_{\mathrm{a}}$ of $\mathbf{1}$ and all of the phosphodiesters were high $\left(\log K_{\mathrm{a}} \sim 4-6\right)$, among which the highest affinity was observed for the dibutyl phosphate $\mathbf{8}^{-}\left(\log K_{\mathrm{a}}=6.2\right)$.

Table 1. Effect of substituents on the ratio of two recognition modes and binding constants $K_{\mathrm{a}}\left[\mathrm{M}^{-1}\right]$ between 1 and phosphodiesters $\mathrm{RO}-\mathrm{PO}_{2}{ }^{-} \mathrm{OR}\left(\mathrm{CH}_{3} \mathrm{CN}\right.$ or $\left.\mathrm{CD}_{3} \mathrm{CN}, 298 \mathrm{~K}\right)$.

\begin{tabular}{|c|c|c|c|c|}
\hline $\begin{array}{c}\text { Guest } \\
\text { anions a }\end{array}$ & $\begin{array}{c}\text { Substituents } \\
\text { (R) }\end{array}$ & $\begin{array}{c}\text { Recognition } \\
\text { mode } 1 b \\
\text { (Threading) }\end{array}$ & $\begin{array}{c}\text { Recognition } \\
\text { mode } 2 b \\
\text { (Folding) }\end{array}$ & $\begin{array}{c}\text { Binding } \\
\text { constant } c \\
\log K_{a}\end{array}$ \\
\hline $3^{-}$ & & $58 \%$ & $42 \%$ & 4.8 \\
\hline $4^{-}$ & $t-\mathrm{Bu}-$ & $87 \%$ & $13 \%$ & 4.5 \\
\hline $5^{-}$ & $\mathrm{MeO}-$ & $72 \%$ & $28 \%$ & 5.4 \\
\hline $6^{-}$ & $\mathrm{O}_{2} \mathrm{~N}$ & $47 \%$ & $53 \%$ & 4.4 \\
\hline $7^{-}$ & & $41 \%$ & $59 \%$ & 4.6 \\
\hline $8^{-}$ & & $10 \%$ & $90 \%$ & 6.2 \\
\hline
\end{tabular}

${ }^{a} n-\mathrm{Bu}_{4} \mathrm{~N}^{+}$salts except for $\mathbf{6}^{-} . \mathbf{6}^{-}$was used as an $i-\mathrm{Pr}_{2} \mathrm{EtNH}^{+}$salt prepared by mixing the corresponding free phosphoric acid and 1.5 equivalents of $i$-Pr $\operatorname{PtN}_{2}$. ${ }^{b}$ Determined by ${ }^{1} \mathrm{H}$ NMR measurements. ${ }^{c}$ Determined by UVvis titration experiments except for $\mathbf{6}^{-}$, which was determined by ${ }^{1} \mathrm{H}$ NMR.

Regardless of the employed phosphodiesters $\left(3^{-}-\mathbf{8}^{-}\right)$, the ${ }^{1} \mathrm{H}$ NMR signals of $a$ and $e$ ( 1 and 5 positions of pyranose) were observed at 5.14-5.21 ppm and 4.42-4.63 ppm for the 'threading' mode, respectively (Figure S22). They appeared in a different region for the 'folding' mode, that is, 5.03-5.08 ppm for proton $a$ and $4.61-4.77 \mathrm{ppm}$ for proton $e$. A similar trend was also observed for the ${ }^{31} \mathrm{P}$ NMR signals of $\mathbf{3}^{-5^{-}}$ included within 1 . The signals were observed at $-5.61-$ $-4.90 \mathrm{ppm}$ for the 'threading' mode, but at $-10.68--9.78$ ppm for the 'folding' mode (Figure S23). These regularities indicated that the structures of both the 'threading' and 'folding' modes are fixed to some extent irrespective of the substituents on the phosphodiesters.

Figure 3 shows the calculated structures of receptor 1 encapsulating diphenyl phosphate $\mathbf{3}^{-}$for each recognition mode (semi-empirical calculation (PM6)). In the 'threading' mode, one phenyl group of $\mathbf{3}^{-}$is included in the cyclodextrin's 'first' cavity, while the other one is placed in the 'second' cavity surrounded by $p$-nitrophenyl groups (Figure 3a). The calculated electrostatic potential map of 1 in the conformation of the 'threading' mode suggests that many $p$-nitrophenyl groups are in the standing conformation to allow the inclusion of the guest, and the 'second' cavity on the electron-deficient $p$-nitrophenyl side has a partial positive charge (Figure 3c). Thus, the model supports that receptor 1 has two distinctive cavities on both sides of the amide groups, and that the recognition pocket of $\mathbf{1}$ is regarded to have a double-conical shape. The para-proton of the phenyl group of $\mathbf{3}^{-}$at the 'second' pocket $\left(k_{1}\right.$ ' in Figure $\left.2 c\right)$ is close to the $p$-nitrophenyl rings of $\mathbf{1}$, which is consistent with the upfield shift of the corresponding NMR signal. In the 'folding' mode, two phenyl groups are placed adjacent to each other in the cyclodextrin's cavity (Figure $3 \mathrm{~b}$ ). This bent conformation of $\mathbf{3}^{-}$is consistent with the downfield shift of the NMR signal of the ortho-proton of $\mathbf{3}^{-}$( $o_{2}$ in Figure 2c), which can be explained by the deshielding effect from the opposite phenyl group. The calculated electrostatic potential map of $\mathbf{1}$ for the 'folding' mode suggests that the $p$-nitrophenyl groups filled the upper space, and some tilted $p$-nitrophenyl groups constituted the positively-charged ceiling of the cyclodextrin's cavity (Figure 3d). Phosphate groups formed multiple hydrogen bonds with the amides in the cavity for both structures. Thus, interesting inclusion modes of the phosphodiesters are observed utilizing the uniquelyrestricted aromatic-amide cyclodextrin framework. 


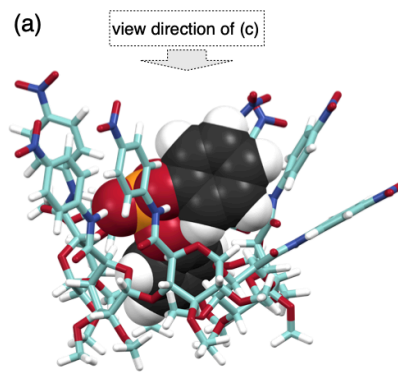

(b)
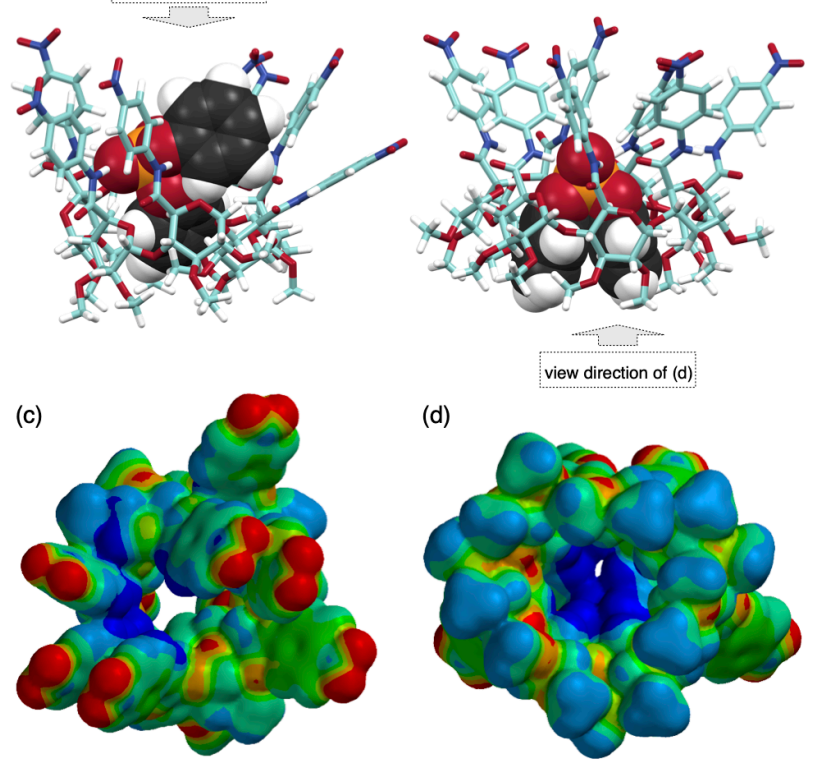

(d)

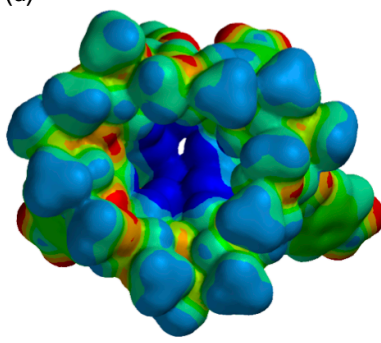

Figure 3. Structures of the two recognition modes of diphenyl phosphate $\left(3^{-}\right)$by 1 obtained by semi-empirical calculations (PM6). (a) and (c) 'Threading' mode. (b) and (d) 'Folding' mode. (a) and (b) 1, stick model; diphenyl phosphate, space-filling model. $\mathrm{H}$, white; $\mathrm{C}$ in $\mathbf{1}$, light green; $\mathrm{C}$ in diphenyl phosphate, black; $\mathrm{N}$, blue; $\mathrm{O}$, red; $\mathrm{P}$, orange. (c) and (d) Calculated electrostatic potential maps of $\mathbf{1}$ for the conformation of each mode ( $3^{-}$has been removed). (c) View from the top. (d) View from the bottom.

In conclusion, we have synthesized a novel cyclodextrin receptor 1 possessing seven $p$-nitrophenylamide groups that shows a strong hydrogen-bonding ability. Receptor $\mathbf{1}$ is a double-conical-shaped host molecule that has two distinct cavities, and recognizes phosphodiesters in two different recognition modes, i.e., the 'threading' mode and the 'folding' mode. The equilibrium is biased toward the 'threading' mode for the guests with bulky or electron-rich substituents, while the 'folding' mode is favored for the flexible guests. Further applications of $\mathbf{1}$ to utilize the precise recognition ability of a series of phosphate anions are now being investigated.

This research was supported by JSPS KAKENHI Grant Numbers JP19H04559 (Coordination Asymmetry), JP19K15578, JP18H01959, JP16H02081, the Asahi Glass Foundation, and the Fukuoka Naohiko Memorial Foundation.

Supporting Information is available on http://dx.doi.org/10.1246/cl.******.

\section{References}

1 A. K. H. Hirsch, F. R. Fischer, F. Diederich, Angew. Chem. Int. Ed. 2007, 46, 338.

2 K. C. Qian, L. Wang, E. R. Hickey, J. Studts, K. Barringer, C. Peng, A. Kronkaitis, J. Li, A. White, S. Mische, B. Farmer, J. Biol. Chem. 2005, 280, 6130 .

3 M. Elias, A. Wellner, K. Goldin-Azulay, E. Chabriere, J. A. Vorholt, T. J. Erb, D. S. Tawfik, Nature 2012, 491, 134.

4 J. D. Farelli, B. D. Galvin, Z. Li, C. Liu, M. Aono, M. Garland, O. 39
S. Carlow, D. Dunaway-Mariano, K. N. Allen, PLoS Pathog. 2014, 10, e1004245

5 A. P. Thompson, W. Salaemae, J. L. Pederick, A. D. Abell, G. W. Booker, J. B. Bruning, K. L. Wegener, S. W. Polyak, ACS Catal. 2018, $8,10774$.

H. Valkenier, A. P. Davis, Acc. Chem. Res. 2013, 46, 2898.

P. A. Gale, E. N. W. Howe, X. Wu, M. J. Spooner, Coord. Chem. Rev. 2018, 375, 333

8 E. Fan, S. A. Van Arman, S. Kincaid, A. D. Hamilton, J. Am. Chem. Soc. 1993, 115, 369.

V. Alcázar, M. Segura, P. Prados, J. Mendoza, Tetrahedron Lett. 1998, 39, 1033.

10 T. Nabeshima, S. Masubuchi, N. Taguchi, S. Akine, T. Saiki, S. Sato, Tetrahedron Lett., 2007, 48, 1595.

11 T. Nakamura, Y. Kaneko, E. Nishibori, T. Nabeshima, Nat Commun. 2017, 8, 129.

12 L. L. Zhao, X. S. Yang, H. Chong, Y. Wang, C. G. Yan, New J. Chem. 2019, 43, 5503.

13 Y. Liu, W. Zhao, C.-H. Chen, A. H. Flood, Science 2019, 365, 159.

14 A. J. McConnell, P. D. Beer, Angew. Chem. Int. Ed. 2012, 51, 5052 .

15 S. K. Dey, A. Basu, R. Chutia, G. Das, RSC Adv. 2016, 6, 26568.

16 Y. Ferrand, I. Huc, Acc. Chem. Res. 2018, 51, 970.

17 N. S. Jung, J. Lee, S. B. Choi, J. Kim, K. Paek, Tetrahedron Lett. 2010, 51, 1291.

18 T. Ema, K. Okuda, S. Watanabe, T. Yamasaki, T. Minami, N. A. Esipenko, P. Anzenbacher, Jr., Org. Lett. 2014, 16, 130.

19 A. Lascaux, G. De Leener, L. Fusaro, F. Topić, K. Rissanen, M. Luhmer and I. Jabin, Org. Biomol. Chem. 2016, 14, 738.

20 S. Kondo, K. Sato, Y. Matsuta, K. Osawa, Bull. Chem. Soc. Jpn. 2018, 91, 875 .

21 J. H. Oh, J. H. Kim, D. S. Kim, H. J. Han, V. M. Lynch, J. L. Sessler, S. K. Kim, Org. Lett. 2019, 21, 4336.

22 C. J. Brown, F. D. Toste, R. G. Bergman, K. N. Raymond, Chem. Rev. 2015, 115, 3012.

23 M. Yamashina, S. Kusaba, M. Akita, T. Kikuchi, M. Yoshizawa, Nat. Commun. 2018, 9, 4227.

24 H. Takezawa, T. Kanda, H. Nanjo, M. Fujita, J. Am. Chem. Soc. 2019, 141, 5112 .

25 A. E. Hargrove, S. Nieto, T. Zhang, J. L. Sessler, E. V. Anslyn, Chem. Rev. 2011, 111, 6603.

26 E. H. Wanderlind, D. G. Liz, A. P. Gerola, R. F. Affeldt, V. Nascimento, L. C. Bretanha, R. Montecinos, L. Garcia-Rio, H. D. Fiedler, F. Nome, ACS Catal. 2018, 8, 3343.

27 R. Salvio, S. Volpi, T. Folcarelli, A. Casnati, R. Cacciapaglia, Org. Biomol. Chem. 2019, 17, 7482.

28 T. Nakamura, S. Yonemura, T. Nabeshima, Chem. Commun. 2019, $55,3872$.

29 T. Kraus, M. Buděšínský, J. Závada, Eur. J. Org. Chem. 2000, 3133. 


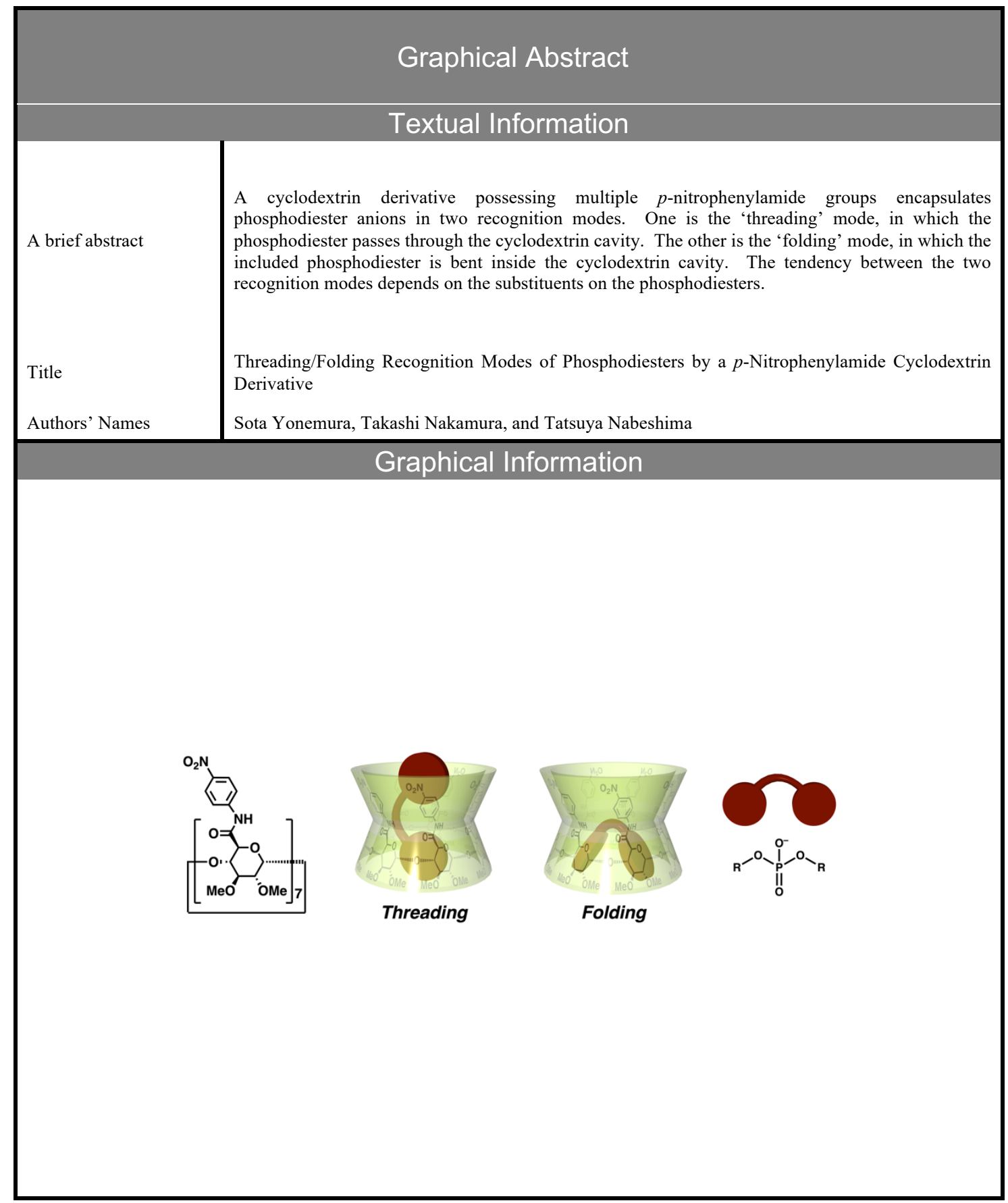

